\title{
Depression and risk of cognitive decline
}

\section{and Alzheimer's disease}

\author{
Results of two prospective community-based studies \\ in The Netherlands
}

\section{I. GEERLINGS, R. A. SCHOEVERS, A. T. F. BEEKMAN, C. JONKER, D. J. H. DEEG, B. SCHMAND, H. J. ADĖR, L. M. BOUTER and W. VAN TILBURG}

\section{Background Depression may be} associated with cognitive decline in elderly people with impaired cognition.

\begin{abstract}
Aims To investigate whether depressed elderly people with normal cognition are at increased risk of cognitive decline and Alzheimer's disease.
\end{abstract}

Methods Two independent samples of older people with normal cognition were selected from the community-based Amsterdam Study of the Elderly (AMSTEL) and the Longitudinal Aging Study Amsterdam (LASA). In AMSTEL, depression was assessed by means of the Geriatric Mental State Schedule. Clinical diagnoses of incident Alzheimer's disease were made using a two-step procedure. In LASA, depression was assessed with the Center for Epidemiologic Studies Depression Scale. Cognitive decline was defined as a drop of $\geqslant 3$ on the MiniMental State Examination at follow-up.

Results Both in the AMSTEL and the LASA sample, depression was associated with an increased risk of Alzheimer's disease and cognitive decline, respectively, but only in subjects with higher levels of education.

\section{Conclusions In a subgroup of more} highly educated elderly people, depression may be an early manifestation of Alzheimer's disease before cognitive symptoms become apparent.

\section{Declaration of interest Grants} detailed in Acknowledgements. No conflict of interest.
Recent studies (Bassuk et al, 1998; Chen et al, 1999; Yaffe et al, 1999) demonstrate the growing interest in whether depression in dementia may be a cause or a consequence of the dementia process. In 1996, Devanand et al reported that depressed mood increased the risk of Alzheimer's disease; in this study, depressed mood was more common in subjects with greater cognitive impairment at baseline, making them more likely to develop Alzheimer's disease. Results of other prospective studies are inconsistent. Dufouil et al (1996) and Henderson et al (1997) did not find a relationship between depression and subsequent cognitive decline, whereas Bassuk et al (1998) and Chen et al (1999) did find such a relationship, but only in subjects in whom cognitive impairment was already apparent. In order to study the nature of the relationship between depression and cognitive decline/dementia further, we investigated whether depressed elderly individuals with normal baseline cognition were at increased risk of cognitive decline and Alzheimer's disease. We used data from two cohorts of elderly people living in the community.

\section{METHODS}

\section{Baseline samples}

Data on incident Alzheimer's disease were obtained from the Amsterdam Study of the Elderly (AMSTEL), whereas data on cognitive decline were obtained from the Longitudinal Aging Study Amsterdam (LASA). Approval was obtained from the Medical Ethics Committee for both studies. The sampling procedures have been described elsewhere (Launer et al, 1993; Deeg et al, 1993; Beekman et al, 1995). In brief, for the AMSTEL study 5666 noninstitutionalised elderly people, aged 6584 years, were selected from 30 general practices across Amsterdam. Within each practice a fixed proportion of people was randomly selected from each of four 5-year age strata (65-69 years to 80-84 years) to obtain equal-sized strata; 4051 people $(71.5 \%)$ gave their written consent and participated in the study. The LASA cohort is based on random, gender- and agestratified (six 5-year age strata from 55 to 84 years) samples drawn from 11 municipal population registries (both urban and rural) in three regions of The Netherlands. The baseline sample of the LASA cohort consists of 3107 people.

Table I Baseline characteristics of the Amsterdam Study of the Elderly study sample ( $n=3147)$, according to the presence or absence of depression

\begin{tabular}{|c|c|c|c|}
\hline & Depression $(n=329)$ & No depression $(n=2818)$ & $P$ \\
\hline Mean age (s.d.), years & $73.6(5.7)$ & $73.7(5.7)$ & $0.82^{\prime}$ \\
\hline \multicolumn{4}{|l|}{ Gender } \\
\hline Male & $62(18.8 \%)$ & 1156 (4I.0\%) & \\
\hline Female & 267 (8I.2\%) & $1662(59.0 \%)$ & $<0.00 \mathrm{I}^{2}$ \\
\hline Mean (s.d.) years of education & $8.0(2.3)$ & $8.5(2.6)$ & $<0.001^{3}$ \\
\hline \multicolumn{4}{|l|}{ Memory complaints } \\
\hline No & $263(80.2 \%)$ & 2563 (91.0\%) & \\
\hline Yes & $65(19.8 \%)$ & $253(9.0 \%)$ & $<0.00 \mathrm{I}^{2}$ \\
\hline \multicolumn{4}{|l|}{ Psychiatric history } \\
\hline No/late onset & $26 I(79.6 \%)$ & 2527 (89.8\%) & \\
\hline Early onset & $67(20.4 \%)$ & $286(10.2 \%)$ & $<0.00 \mathrm{I}^{2}$ \\
\hline
\end{tabular}




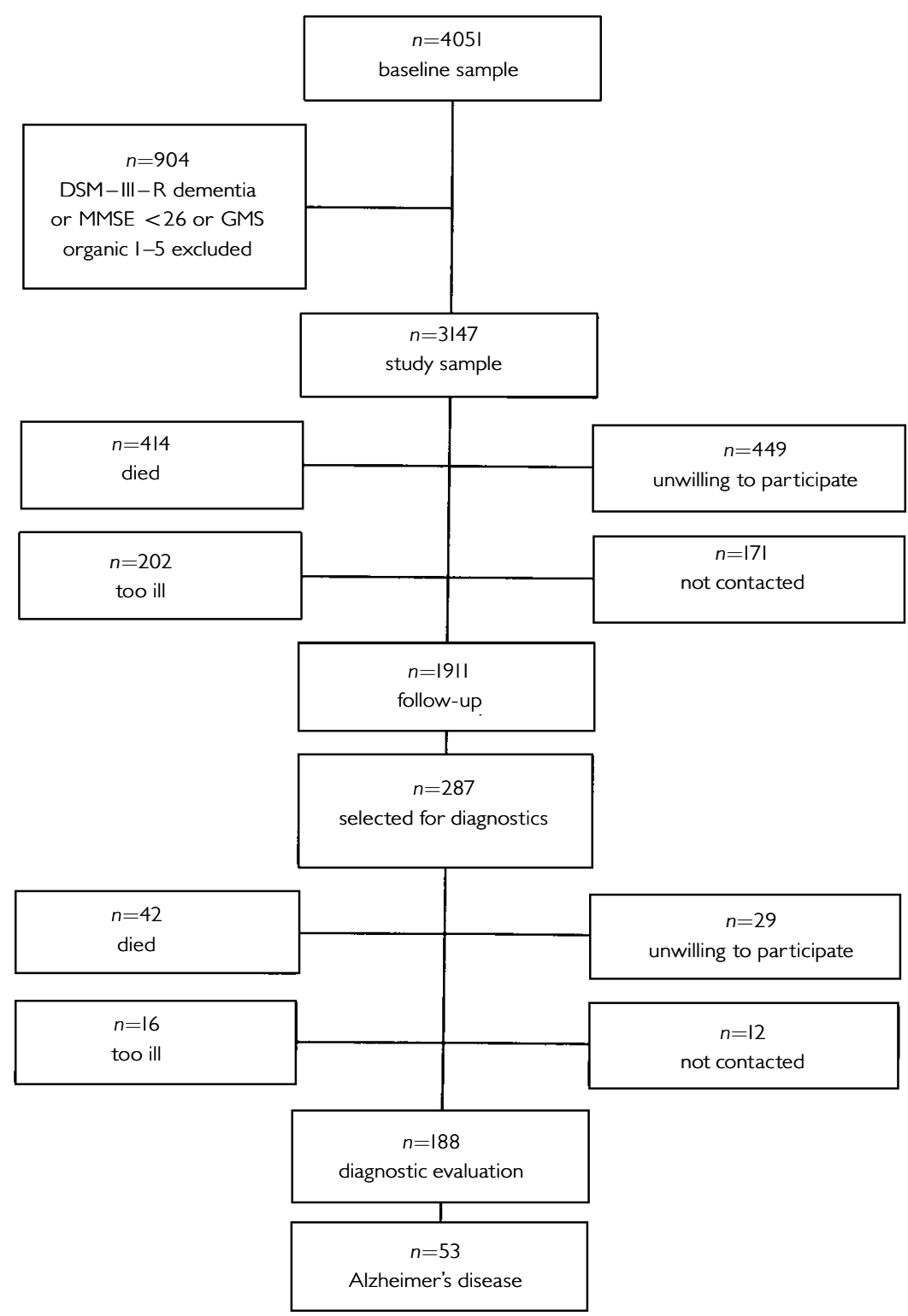

Fig. I Amsterdam Study of the Elderly sample; numbers available and not available for follow-up.

\section{Baseline measurements and study samples}

\section{AMSTEL}

In 1990-1991 trained lay people interviewed all 4051 participants at home. The interview comprised the Dutch version of the Geriatric Mental State Schedule (GMSS) (Copeland et al, 1976; Gurland et al, 1976; Hooijer et al, 1991), questions on socio-demographic characteristics, current health status, medical history, and four mental status tests, including the MiniMental State Examination (MMSE) (Folstein et al, 1975). Depression was measured using the GMSS, in conjunction with its computerised diagnostic system AGECAT (Dewey \& Copeland, 1986). The GMSS is a structured interview aimed at identifying various psychiatric disorders, which has been specifically designed for use with elderly individuals. AGECAT consists of the application of hierarchical rules to the items of the GMSS in order to reach a diagnosis for various psychiatric disorders (e.g. depression and dementia syndromes) with different levels of confidence. The presence and absence of depression were indicated by GMS-AGECAT depression syndrome levels 3-6 and 0-2, respectively.

To select a study sample with normal cognition, a cohort without dementia was first selected by excluding from the baseline sample all subjects $(n=273)$ with a DSMIII-R dementia diagnosis (American Psychiatric Association, 1987) (for a more detailed description see Jonker et al, 1998) or a GMS-AGECAT dementia diagnosis (i.e. organic illness syndrome levels of 3-5). Second, from this cohort without dementia all subjects with sub-threshold levels of dementia were excluded: that is, with GMS-AGECAT dementia levels of 1-2 or MMSE scores of 25 and below $(n=631)$. In all, 904 subjects were excluded, resulting in a study sample of 3147 non-demented subjects with normal cognition (i.e. MMSE scores of 26-30 and GMS-AGECAT organic illness score 0).

\section{LASA}

In 1992-1993, trained lay people interviewed all 3107 participants at home. Cognitive functioning was measured with the MMSE. Depressive symptoms were measured with the Dutch version of the Center for Epidemiologic Studies Depression Scale (CES-D) (Beekman et al, 1997). This is a 20-item self-report scale developed to measure current depressive symptoms in the community. The CES-D generates a total score which can range from 0 to 60 . In order to identify respondents with clinically relevant levels of depression, the generally used cut-off score of $\geqslant 16$ was also used. To minimise overlap between affective symptoms and symptoms possibly due to physical illness, analyses were also performed using a sub-scale constructed of seven items of the CES-D reflecting negative affect (bothered, blues, depressed, fearful, lonely, cried and sad) (Radloff \& Teri, 1986). Scores on the negative affect subscale range from 0 to 20 points, with higher scores indicating greater severity.

For the present study, a sample with normal cognition was selected by excluding all subjects of the baseline sample with MMSE scores below 26, resulting in a study sample of 2399 people.

\section{Follow-up measurements \\ AMSTEL}

At follow-up in 1994, all the subjects who were available were interviewed again by trained lay people, using the same interview procedure as in 1990-91. A subsample of subjects who were suspected of having developed dementia were invited for diagnostic evaluation. The screening procedure and diagnostic evaluation have been described elsewhere (Geerlings et al, 1999). In brief, all subjects with MMSE scores of 23 or less, or with impairment in 
Table 2 Baseline characteristics of the Amsterdam Study of the Elderly sample $(n=3147)$ for subjects who were and were not available for follow-up in 1994

\begin{tabular}{|c|c|c|c|}
\hline & Interview $(n=|9| \mid)$ & Lost to follow-up ( $n=1236)$ & $P$ \\
\hline Mean age (s.d.), years & $73.1(5.5)$ & $74.6(5.7)$ & $<0.00 \mathrm{I}^{\prime}$ \\
\hline \multicolumn{4}{|l|}{ Gender } \\
\hline Male & 721 (37.7\%) & 497 (40.2\%) & \\
\hline Female & 1190 (62.3\%) & 739 (59.8\%) & $0.16^{2}$ \\
\hline Mean (s.d.) years of education & $8.6(2.6)$ & $8.2(2.4)$ & $<0.00 \mathrm{I}^{3}$ \\
\hline \multicolumn{4}{|l|}{ Memory complaints } \\
\hline No & $1699(89.0 \%)$ & II27 (91.3\%) & \\
\hline Yes & $210(11.0 \%)$ & $108(8.7 \%)$ & $0.04^{2}$ \\
\hline \multicolumn{4}{|l|}{ Psychiatric history } \\
\hline No/late onset & $1692(88.7 \%)$ & $1069(88.9 \%)$ & \\
\hline Early onset & $216(11.3 \%)$ & 137 (II.I\%) & $0.86^{2}$ \\
\hline \multicolumn{4}{|l|}{ Depression } \\
\hline Absent & 1725 (90.3\%) & $1093(88.4 \%)$ & \\
\hline Present & $186(9.7 \%)$ & 143 (II.6\%) & $0.10^{2}$ \\
\hline
\end{tabular}

The numbers do not always add up to 3147 because of missing values on some variables.

I. $t$-test.

2. $\chi^{2}$-test.

3. Mann-Whitney U-test.

Table 3 Crude and adjusted odds ratios (ORs), with corresponding $95 \%$ confidence intervals (Cls), for the association between depression, age, gender, education, memory complaints, psychiatric history and incident Alzheimer's disease (Amsterdam Study of the Elderly)

\begin{tabular}{lcc}
\hline & Crude OR (95\% Cl) & Adjusted' OR (95\% Cl) \\
\hline Depression (yes v. no) & $2.21(\mathrm{I} .09-4.48)$ & $\mathrm{I} .67(0.76-3.63)$ \\
Age (per year increase) & $\mathrm{I} .19(\mathrm{I} .12-\mathrm{I} .26)$ & $\mathrm{I} .18(\mathrm{I} . \mathrm{II}-\mathrm{I} .25)$ \\
Gender (women v. men) & $2.10(\mathrm{I} .10-4.03)$ & $\mathrm{I} .44(0.73-2.84)$ \\
Education (per year increase) & $0.8 \mathrm{I}(0.7 \mathrm{I}-0.93)$ & $0.86(0.75-0.99)$ \\
Memory complaints (yes v. no) & $2.79(\mathrm{I} .47-5.30)$ & $2.79(\mathrm{I} .39-5.59)$ \\
Psychiatric history (no/late onset v. early onset) & $0.3 \mathrm{I}(0.08-\mathrm{I} .29)$ & $0.30(0.07-\mathrm{I} .26)$ \\
\hline
\end{tabular}

I. Adjusted for all other variables mentioned in the table.

Table 4 Odds ratios $(95 \% \mathrm{Cl})$ adjusted for all other variables of the association between depression, age, gender, memory complaints and psychiatric history and incident Alzheimer's disease, for subjects with $\leqslant 8$ years, and $>\mathbf{8}$ years of education, respectively (Amsterday Study of the Elderly)

\begin{tabular}{lcc}
\hline & $\begin{array}{c}\leqslant 8 \text { years of education } \\
n=87 \text { I OR }(95 \% \mathrm{Cl})^{\prime}\end{array}$ & $\begin{array}{c}>8 \text { years of education } \\
n=1036 \text { OR }(95 \% \mathrm{Cl})^{\prime}\end{array}$ \\
\hline Depression (yes v. no) & $0.63(0.18-2.19)$ & $5.31(1.88-15.00)$ \\
Age (per year increase) & $1.17(1.08-1.27)$ & $1.19(1.09-1.29)$ \\
Gender (women v. men) & $2.52(0.86-7.38)$ & $0.96(0.38-2.46)$ \\
Memory complaints (yes v. no) & $2.15(0.77-5.97)$ & $3.27(1.26-8.49)$ \\
Psychiatric history (no/late onset v. early onset) & not added (not enough & $0.72(0.15-3.46)$ \\
& observations) & \\
\hline
\end{tabular}

I. Adjusted for all other variables mentioned in the table. orientation in time, recent memory or learning, were invited for diagnostic evaluation. During home visits, physicians specifically trained for this purpose administered the Cambridge Examination for Mental Disorders in the Elderly (including a structured psychiatric interview, the Cambridge Cognitive Examination, and a physical examination) (Roth et al, 1988). Clinical diagnoses of Alzheimer's disease were made according to DSM-IV criteria (American Psychiatric Association, 1994). Diagnoses were determined during weekly meetings with the senior neurologist (C.J.) and the neuropsychologist (M.I.G.).

\section{LASA}

At follow-up in 1995-1996, all the respondents who were available were interviewed again during home visits, using the same interview procedure as was used at baseline.

\section{Statistical analyses \\ AMSTEL}

Multiple logistic regression analyses were performed to assess the effect of depression on incident Alzheimer's disease. Covariates used in the analyses were age, gender, level of education, memory complaints and psychiatric history. Level of education was expressed as the number of full-time years of education needed to obtain the highest grade of education completed. In the analyses, it was used both as a continuous and as a dichotomous variable (dichotomised at the median of the study sample into $\leqslant 8$ years $v$. $>8$ years of education; 8 years of education is comparable with 2 years of secondary education after having completed primary school). Memory complaints were assessed by the question: "Do you have complaints about your memory?" Answers were coded "yes" or "no". Psychiatric history was assessed by the question: "Have you ever had emotional or nervous illness requiring treatment?" If answered positively, age of onset was assessed. Psychiatric history was categorised as no history, or first onset at age 60 or above, $v$. a psychiatric history before age 60 .

First, the analyses were performed, with adjustments for the potential confounders. Second, since the strength of the association between depression and incident Alzheimer's disease may be different for people with different demographic characteristics and for those with or without memory complaints or psychiatric 
history, we also tested possible interactions between depression and age, gender, education, memory complaints and psychiatric history, respectively.

\section{LASA}

Multiple logistic regression analyses were performed to assess the effect of depressive symptoms on cognitive decline. Cognitive decline was defined as a drop of 3 or more points ( $>1$ standard deviation) in the MMSE at follow-up. Depressive symptoms were used in the analyses as a continuous variable (total CES-D score, and negative affect score), as a dichotomised variable $(\mathrm{CES}-\mathrm{D} \geqslant 16 v .<16)$, and as a categorical variable (the core depression item from the CES-D ("during the past week I felt depressed") was used to examine the association between mild depressed mood ("some of the time" $v$. "no") and incident cognitive decline and a severe depressed mood ("often/always" $v$. "no") and incident cognitive decline, respectively. The same covariates as in the AMSTEL sample were used. However, in LASA, data on psychiatric history were not collected and were not therefore used in the analyses of the LASA data. Interactions between the different definitions of depression and the covariates were also tested. Finally, to correct for possible differences in baseline MMSE scores between the two groups with different educational levels, we also performed the analyses with additional adjustments for baseline MMSE score (range 26-30).

\section{RESULTS}

\section{AMSTEL}

Table 1 shows the baseline characteristics of the AMSTEL study sample $(n=3147)$, according to the presence or absence of depression. The follow-up lasted 3.2 years, on average. Figure 1 shows the numbers of people who were available for follow-up and who were lost to follow-up. At followup, 53 people received a diagnosis of Alzheimer's disease.

Table 2 shows the baseline characteristics for those who were and were not available for follow-up.

Table 3 shows the crude and adjusted odds ratios of incident Alzheimer's disease associated with depression, age, gender, education, memory complaints and psychiatric history. Depression moderately increased the risk of Alzheimer's disease.
Table 5 Baseline characteristics of the Longitudinal Aging Study Amsterdam study sample $(n=2399)$, according to the presence or absence of depressive symptoms

\begin{tabular}{|c|c|c|c|}
\hline & CES-D score $\geqslant 16(n=296)$ & CES-D score $<16(n=2092)$ & $P$ \\
\hline Mean age (s.d.), years & $70.7(8.7)$ & $69.2(8.5)$ & $0.004^{\prime}$ \\
\hline \multicolumn{4}{|l|}{ Gender } \\
\hline Male & 104 (35.1\%) & 1060 (50.7\%) & \\
\hline Female & $192(64.9 \%)$ & 1032 (49.3\%) & $<0.00 \mathrm{I}^{2}$ \\
\hline \multicolumn{4}{|l|}{ Education } \\
\hline$\leqslant 8$ years & $186(63.1 \%)$ & 1194 (57.3\%) & \\
\hline$>8$ years & $109(36.9 \%)$ & 891 (42.7\%) & $0.054^{2}$ \\
\hline \multicolumn{4}{|l|}{ Memory complaints } \\
\hline No & 187 (63.2\%) & 1657 (79.2\%) & \\
\hline Yes & $109(36.8 \%)$ & 434 (20.8\%) & $<0.001^{2}$ \\
\hline
\end{tabular}

The numbers do not always add up to 2399 because of missing values on some variables. I. $t$-test.

2. $\chi^{2}$-test.

CES-D, Center for Epidemiologic Studies Depression Scale.

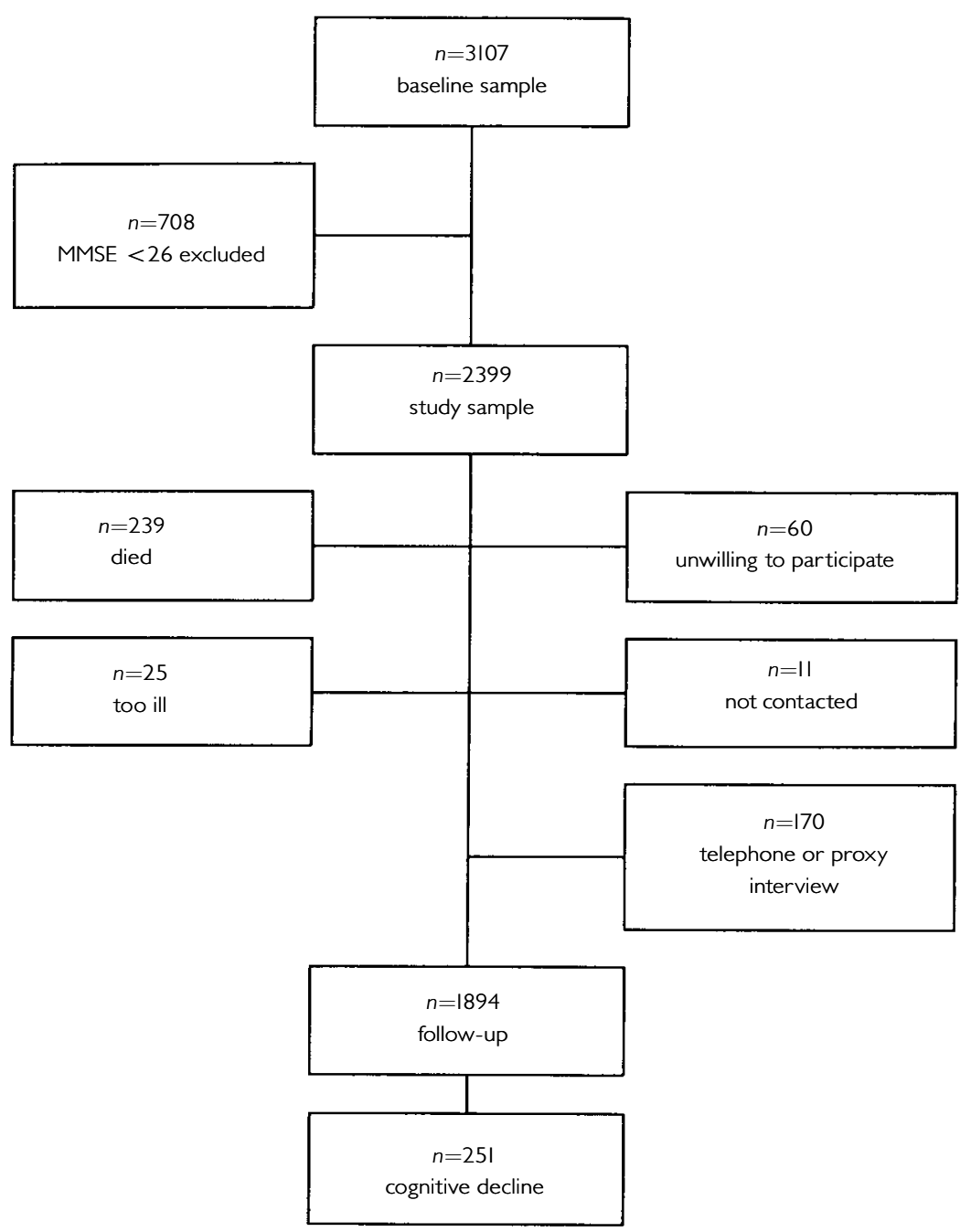

Fig. 2 Longitudinal Aging Study Amsterdam sample; numbers available and not available for follow-up. 
Table 6 Baseline characteristics of the Longitudinal Aging Study Amsterdam sample $(n=2399)$ for subjects who were and were not available for follow-up

\begin{tabular}{|c|c|c|c|}
\hline & Interview $(n=1894)$ & Lost to follow-up $(n=505)$ & $P$ \\
\hline Mean CES-D score (s.d.) & $7.1(7.1)$ & $8.2(7.7)$ & $0.005^{\prime}$ \\
\hline \multicolumn{4}{|l|}{ CES-D score } \\
\hline$<16$ & $1669(88.4 \%)$ & 423 (84.4\%) & \\
\hline$\geqslant 16$ & 218 (11.6\%) & 78 (15.6\%) & $0.015^{2}$ \\
\hline Mean negative affect (s.d.) & $1.8(2.7)$ & $2.2(3.1)$ & 0.0591 \\
\hline \multicolumn{4}{|l|}{ Felt depressed } \\
\hline Rarely or never & I57I (83.0\%) & 40 I (79.9\%) & \\
\hline Some of the time & 253 (13.4\%) & $65(12.9 \%)$ & \\
\hline Often/always & $68(3.6 \%)$ & 36 (7.2\%) & $0.002^{2}$ \\
\hline Mean age (s.d.), years & $68.5(8.3)$ & $72.8(8.4)$ & $<0.001^{3}$ \\
\hline \multicolumn{4}{|l|}{ Gender } \\
\hline Male & $892(47.1 \%)$ & $278(55.0 \%)$ & \\
\hline Female & $1002(52.9 \%)$ & 227 (45.0\%) & $0.001^{2}$ \\
\hline Mean baseline MMSE (s.d.) & $28.2(1.3)$ & $27.8(1.3)$ & >0.00 I \\
\hline \multicolumn{4}{|l|}{ Memory complaints } \\
\hline No & 1463 (77.3\%) & 387 (76.6\%) & \\
\hline Yes & $430(22.7 \%)$ & II 8 (23.4\%) & $0.757^{2}$ \\
\hline \multicolumn{4}{|l|}{ Education } \\
\hline$\leqslant 8$ years & 1054 (55.7\%) & 334 (66.3\%) & \\
\hline$>8$ years & $838(44.3 \%)$ & $170(33.7 \%)$ & $<0.001^{2}$ \\
\hline
\end{tabular}

Not all numbers add up to 2339 because of missing values on some variables.

I. Mann-Whitney $U$-test.

2. $\chi^{2}$-test.

3. $t$-test.

CES-D, Center for Epidemiologic Studies Depression Scale; MMSE, Mini-Mental State Examination.

In the multivariate model, with adjustments for all other variables, the odds ratio of Alzheimer's disease associated with depression decreased towards a statistically nonsignificant level.

Interaction terms added to the model containing all covariates showed that the association between depression and Alzheimer's disease was modified by education (centred variable) (likelihood ratio test, $P=0.023)$. The interaction term was also statistically significant when education was used as a dichotomous variable $(P=0.004)$. There were no statistically significant interactions between depression and memory complaints or between depression and psychiatric history, nor were there between depression and age or gender.

To interpret the modifying effect of education on the association between depression and incident Alzheimer's disease, we performed logistic regression analyses within two groups having had education to different levels (dichotomised at the median value of the study sample). Depression greatly increased the risk of Alzheimer's disease among subjects with more than 8 years of education, but not among subjects with 8 years of education or less (Table 4).

\section{LASA}

Table 5 shows the baseline characteristics of the LASA study sample $(n=2399)$ according to the presence or absence of depression. The duration of follow-up averaged 3.1 years. Figure 2 shows the numbers of people who were available for follow-up and who were lost to follow-up.

Table 6 shows the baseline characteristics for subjects who were and were not available for follow-up. At follow-up, 251 people showed a drop of three or more points on the MMSE

Multiple regression analyses adjusting for age, gender, education and memory complaints showed that neither higher scores on the continuous CES-D nor CES-D scores of $\geqslant 16$ were associated with subsequent cognitive decline (adjusted odds ratio $(\mathrm{OR})=1.01$; $95 \%$ confidence interval $(\mathrm{CI})=0.99-1.03$ and $\mathrm{OR}=1.07 ; 95 \% \mathrm{CI}=0.70-1.62$, respectively). However, negative affect increased the risk of cognitive decline (adjusted OR per point increase $=1.05 ; 95 \% \mathrm{CI}=1.00$ 1.09). A severe depressed mood was also associated with subsequent cognitive decline (adjusted $\mathrm{OR}=1.97 ; 95 \% \mathrm{CI}=1.09$ 3.56), but a mild depressed mood was not $(\mathrm{OR}=1.05 ; 95 \% \mathrm{CI}=0.71-1.57)$.

When the interaction between CES-D (centred variable) and education (dichotomous variable) was entered into the model containing CES-D (as a continuous variable), age, gender, education and memory complaints, the association between depressive symptoms and cognitive decline was modified by education $(P=0.012)$. A similar result was found when the dichotomised variable was used in the interaction term $(P=0.047)$ and when negative affect was used in the interaction term $(P=0.017)$. Finally, the interaction between a severe depressed mood and education was of borderline significance $(P=0.076)$, but the interaction between mild depressed mood and education was not $(P=0.74)$. No significant interactions between depressive symptoms and one of the other covariates was found.

Logistic regression analyses stratified by level of education showed that depressive symptoms were associated with cognitive decline among subjects with more than 8 years of education, but not among those with 8 years of education or less (Table 7). Although the association between CES-D scores of $\geqslant 16$ and cognitive decline was attenuated after adjusting for the possible confounders, higher scores on the continuous CES-D, higher negative affect scores and a severe depressed mood remained predictive of subsequent cognitive decline (Table 7). Among less-educated subjects, no association between depressive symptoms and cognitive decline was found, regardless of the definition of depressive symptoms. When the multivariate analyses were performed with additional adjustments for baseline MMSE score, the results were very similar.

\section{DISCUSSION}

We investigated whether depression in older people with normal cognition was associated with subsequent cognitive decline and incident Alzheimer's disease. The findings in both AMSTEL and LASA showed that depression increased the risk of Alzheimer's disease and cognitive decline, respectively, but only among people with higher levels of education. 
Table 7 Associations (odds ratios with 95\% confidence intervals) between four definitions of depressive symptoms and subsequent cognitive decline, according to level of education (Longitudinal Aging Study Amsterdam)

\begin{tabular}{|c|c|c|}
\hline & \multicolumn{2}{|c|}{ Education } \\
\hline & $>8$ years $(n=838)$ & $\leqslant 8$ years $(n=1054)$ \\
\hline & OR $(95 \% \mathrm{Cl})$ & OR $(95 \% \mathrm{Cl})$ \\
\hline \multirow[t]{3}{*}{ CES-D score (per point increase) } & $1.05(1.02-1.08)^{\prime}$ & $1.00(0.98-1.02)^{\prime}$ \\
\hline & $1.04(1.01-1.08)^{2}$ & $1.00(0.98-1.02)^{2}$ \\
\hline & $1.05(1.01-1.08)^{3}$ & $1.00(0.98-1.02)^{3}$ \\
\hline \multirow[t]{3}{*}{ CES-D score $(\geqslant 16 v .<16)$} & $2.00(1.05-3.81)^{1}$ & $0.83(0.50-1.40)^{\prime}$ \\
\hline & $1.79(0.9 \mathrm{I}-3.5 \mathrm{I})^{2}$ & $0.83(0.49-I .4 I)^{2}$ \\
\hline & $1.83(0.93-3.60)^{3}$ & $0.84(0.49-1.43)^{3}$ \\
\hline \multirow[t]{3}{*}{ Negative affect score (per point increase) } & $1.14(1.06-1.24)^{1}$ & $1.02(0.96-1.07)^{1}$ \\
\hline & $1.13(1.04-1.22)^{2}$ & $1.01(0.96-1.07)^{2}$ \\
\hline & $1.13(1.04-1.23)^{3}$ & $1.02(0.96-1.08)^{3}$ \\
\hline \multicolumn{3}{|l|}{ Felt depressed (reference: rarely or never) } \\
\hline \multirow[t]{3}{*}{ Some of the time } & $\mathrm{I} .15(0.57-2.3 \mathrm{I})^{1}$ & $1.06(0.67-1.69)^{1}$ \\
\hline & I.II $(0.54-2.29)^{2}$ & $1.04(0.65-1.68)^{2}$ \\
\hline & $1.15(0.56-2.38)^{3}$ & $1.03(0.64-1.67)^{3}$ \\
\hline \multirow[t]{3}{*}{ Often/always } & $4.39(1.75-10.99)^{\prime}$ & $\mathrm{I} .55(0.75-3.2 \mathrm{I})^{1}$ \\
\hline & $3.92(|.47-| 0.4 \mid)^{2}$ & $1.44(0.68-3.05)^{2}$ \\
\hline & $4.10(1.54-10.90)^{3}$ & $1.49(0.70-3.16)^{3}$ \\
\hline
\end{tabular}

The numbers do not add up to 1894 because of some missing values on the variable education.

I. Crude associations.

2. Adjusted for age, gender and memory complaints.

3. Adjusted for age, gender, memory complaints and baseline Mini-Mental State Examination score.

CES-D, Center for Epidemiologic Studies Depression Scale.

\section{Depression as a psychological reaction}

Most commonly, two explanations have been suggested for the frequent occurrence of depression in Alzheimer's disease patients. First, depression may be a psychological reaction to perceived cognitive decline (Migliorelli et al, 1995) that may particularly occur in mild stages of Alzheimer's disease, when patients may still be aware of their failing cognitive capacities (Ott et al, 1992). Although this explanation implies that depression is a consequence of the dementia process, depressive symptoms may become apparent before the diagnosis of Alzheimer's disease is made. The development of the illness is a gradual process that may start long before the diagnostic criteria are met, and patients may notice these changes in cognition at an early stage of the disease, and develop depressive symptoms as a reaction. However, although the prevalence of depression has been found to be inversely related to the severity of dementia (Fischer et al, 1990), others found no association between depression and insight into cognitive deficits (Verhey et al, 1993; Cummings et al, 1995), suggesting that the association is not purely a psychological one. Moreover, if the explanation were psychological, the association between depression and incident Alzheimer's disease would be modified by memory complaints, since these may reflect realistic self-observation of cognitive decline (Geerlings et al, 1999). Although memory complaints were more prevalent among depressed subjects than among non-depressed subjects, we did not find that the association between depression and incident Alzheimer's disease was stronger among those with memory complaints. Finally, a psychological mechanism does not explain the observed interaction between depression and education.

\section{Depression as an early symptom of Alzheimer's disease}

Our data may agree better with the second explanation, which hypothesises that depression is an early symptom of the neuropathological process of Alzheimer's disease.
Studies on neurochemical and neuropathological changes in the brain of people with Alzheimer's disease suggest either that they may have lower thresholds for depressive disorders, or that the dementia process contributes to the development of depression (Zubenko \& Moossy, 1988; Zweig et al, 1988; Förstl et al, 1992). It could be that depression as an early symptom or a subclinical expression of Alzheimer's disease may have become more overt in more highly educated people, who may have greater 'reserve capacity'. This may be a 'brain reserve', reflected in a greater number of large neurons, greater brain weight or increased neocortical synaptic density (Katzman, 1993), or a 'cognitive reserve', reflected in greater intellectual capacity or coping skills more adequate to deal with the dementia process (Stern et al, 1994). Several studies suggest that the neuropathological process of Alzheimer's disease may be more advanced in elderly people with higher levels of educational and occupational attainment than in those with lower levels (Stern et al, 1995a,b), despite similar clinical severity. Thus, it is possible that in people with greater (cognitive) reserve the cognitive symptoms of Alzheimer's disease may be delayed, but not the depressive symptoms of the disease.

In the LASA sample, the association between depressive symptoms and cognitive decline became stronger when the analyses were restricted to affective symptoms and to a more severe form of these symptoms. The observation that a severe depressed mood was strongly associated with subsequent cognitive decline may also support the hypothesis that depression is an early manifestation of a dementia process. A severe depressed mood is a more specific indicator of major depression (Meyers \& Bruce, 1998), and this could indicate some biological relationship rather than a purely psychological one (Migliorelli et al, 1995).

\section{Psychiatric history}

In the AMSTEL sample, no modifying effect of psychiatric history on the association between depression and Alzheimer's disease was observed, as might have been expected if late-onset depression were associated with organic illness (Alexopoulos et al, 1988). However, there may not have been enough observations in the subgroups for the interaction term to be statistically significant, since at baseline the majority $(80 \%)$ of depressed people reported no 
psychiatric history or a late-onset history. This finding in itself suggests that the depression that we observed in our study sample is indicative of a dementia process.

\section{LASA and AMSTEL}

The most notable strength of this study was that we were able to analyse data from two independent samples. Both the AMSTEL and the LASA studies are prospective community-based studies in The Netherlands; both cohorts contain elderly people who were interviewed at home, and the follow-up interval between the first and the second assessment was very similar in both studies. An important difference is that the samples were drawn independently of one another and for different purposes. Moreover, depression and cognitive decline or dementia were assessed using different instruments. In the AMSTEL study, depression was assessed with the GMSS, which is an instrument based on the British tradition, while the CES-D, used in the LASA study, is more widely used in the USA. Furthermore, although both instruments measure a broad spectrum of depressive symptoms, the CES-D contains fewer items than the GMSS and does not rely on the clinical judgement of the interviewer. With respect to the outcome variable, the differences between a clinical diagnosis of Alzheimer's disease and cognitive decline based on a subtraction score on the MMSE may be even greater. In view of these differences in both determinant and outcome, it is striking that the results of both the LASA and the AMSTEL studies demonstrated that depression increased the risk of cognitive decline and Alzheimer's disease only among subjects with higher levels of education.

\section{Loss to follow-up}

We have to consider that our findings may be biased because of differential loss to follow-up. Particularly in the AMSTEL sample, the proportion of subjects lost to follow-up was considerable. Although depressed people were not more likely to be lost to follow-up in this sample, in the LASA sample depressed subjects did become lost more often. However, we consider it unlikely that in the LASA sample the great difference in odds ratios between the two groups with different levels of education for those with a severe depressed mood is explained by differential loss to follow-up alone.

\section{CLINICAL IMPLICATIONS}

Depression, and in particular a severe depressed mood, may be an early or subclinical manifestation of cognitive decline and Alzheimer's disease in elderly people with higher levels of education.

- In these people, commonly used mental status tests such as the Mini-Mental State Examination are inadequate to detect subtle cognitive decline.

- The subclinical expression of cognitive decline or dementia may be different for different subgroups of elderly people, according to their educational level.

\section{LIMITATIONS}

- Although our data confirm the clinical impression that late-onset depression is associated with organic illness, it is uncertain whether the question about psychiatric history in the Amsterdam Study of the Elderly study indeed assessed a history of depression.

- The nature of this study does not permit any inferences to be drawn regarding possible pathogenetic mechanisms that may underlie the observed association between depression and incident Alzheimer's disease.

Based on the findings of this study, no suggestions can be made as to whether treatment of depression would result in a delay of the clinical expression of cognitive decline and dementia.

MIRJAM I. GEERLINGS, MSc, LEX M. BOUTER, PhD, Institute for Research in Extramural Medicine; ROBERT A SCHOEVERS, MD, AARTJAN T. F. BEEKMAN, MD, CEES JONKER, MD, DORLY J. H. DEEG, PhD, WILLEM VAN TILBURG, MD, Institute for Research in Extramural Medicine and Department of Psychiatry; HERMAN J. ADÈR, PhD, Institute for Research in Extramural Medicine and Department of Clinical Epidemiology and Biostatistics, Vrije Universiteit, Amsterdam; BEN SCHMAND, PhD, Department of Neurology, Universiteit van Amsterdam, The Netherlands

Correspondence to: M. I. Geerlings, Department of Epidemiology \& Biostatistics, Erasmus Medical Center Rotterdam, PO Box 1738, 3000 DR Rotterdam, The Netherlands. Tel: +31 104087478 ; Fax: +31 10408 9382; e-mail: geerlings@epib.fgg.eur.nl

(First received 27 May 1999, final revision 20 October 1999, accepted 27 October 1999)

\section{Highly educated elderly at greater risk}

We observed in two independent communitybased samples that depressed elderly people with normal cognition and higher levels of education were at increased risk of incident cognitive decline and Alzheimer's disease. The data do not support the hypothesis that depression is primarily a psychological reaction to deteriorating cognitive capacities. Instead, they support the hypothesis that depression is a subclinical expression or an early symptom of an underlying dementia process, which may become apparent in a subgroup of more highly educated older people in whom commonly used mental status tests do not yet detect a decline from a previous level of cognitive functioning. The data do not provide proof of possible pathogenetic mechanisms, however, and it remains to be determined whether treatment of depression would result in a delay of the clinical expression of cognitive decline and dementia.

\section{ACKNOWLEDGEMENTS}

The Amsterdam Study of the Elderly (AMSTEL) was supported by grants from The Netherlands Health Research Promotion Programme (SGO) and The Netherlands Fund of Mental Health (NFGV). The AGECAT computer program was installed with the kind cooperation and final authorisation of Michael 
E. Dewey, Department of Psychiatry, University of Liverpool. The Longitudinal Aging Study Amsterdam is financed primarily by the Ministry of Welfare, Health and Sports of The Netherlands.

\section{REFERENCES}

Alexopoulos, G. S., Young, R. C., Meyers, B. S., et al (1988) Late-onset depression. Psychiatric Clinics of North America, II, $101-115$.

American Psychiatric Association (1987) Diagnostic and Statistical Manual of Mental Disorders (3rd edn, revised) (DSM-III-R). Washington, DC: APA

- (1994) Diagnostic and Statistical Manual of Mental Disorders (4th edn) (DSM-IV). Washington, DC: APA.

Bassuk, S. S., Berkman, L. F. \& Wypij, D. (1998) Depressive symptomatology and incident cognitive decline in an elderly community sample. Archives of General Psychiatry, 55, 1073-1081.

Beekman, A.T. F., Deeg, D. J. H., VanTilburg, T., et al (1995) Major and minor depression in later life: a study of prevalence and risk factors. Journal of Affective Disorders, 36, 65-75.

__, _ , Van Limbeek, J., et al (1997) Criterion validity of the Center for Epidemiologic Studies Depression scale (CES-D): results from a community-based sample of older subjects in the Netherlands. Psychological Medicine, 27, 23I-235.

Chen, P., Ganguli, M., Mulsant, B. H., et al (1999) The temporal relationship between depressive symptoms and dementia. Archives of General Psychiatry, 56 $26 \mid-266$.

Copeland, J. R. M., Kelleher, M. J., Kellett, J. M., et al (1976) A semi-structured clinical interview for the assessment of diagnosis and mental state in the elderly: the Geriatric Mental State Schedule. I. Development and reliability. Psychological Medicine, 6, 439-449.

Cummings, J. L., Ross, W., Absher, J., et al (1995) Depressive symptoms in Alzheimer's disease: assessment and determinants. Alzheimer Disease \& Associated Disorders, 9, 87-93.

Deeg, D. J. H., Knipscheer, C. P. M. \& VanTilburg, W. (eds) (1993) Autonomy and Well-being in the Aging Population: Concepts and Design of the Longitudinal Aging Study Amsterdam. Bunnik, The Netherlands: Netherlands Institute of Gerontology.

Devanand, D. P., Sano, M., Tang, M. X., et al (1996)

Depressed mood and the incidence of Alzheimer's disease in the elderly living in the community. Archives of General Psychiatry, 53, 175-182.

\section{Dewey, M. E. \& Copeland, J. R. M. (1986)}

Computerised psychiatric diagnosis in the elderly: AGECAT. Journal of Microcomputer Applications, $\mathbf{9}$ 135-140.

Dufouil, C., Fuhrer, R., Dartigues, J. F., et al (1996) Longitudinal analysis of the association between depressive symptomatology and cognitive deterioration. American Journal of Epidemiology, 144, 634-641.

Fischer, P., Simanyi, M. \& Danielczyk, W. (1990) Depression in dementia of the Alzheimer type and in multi-infarct dementia. American journal of Psychiatry, 147, 1484-1487.

Förstl, H., Burns, A., Luthert, P., et al (1992) Clinica and neuropathological correlates of depression in Alzheimer's disease. Psychological Medicine, 22. 877-884

Folstein, M. F., Folstein, S. E. \& McHugh, P. R. (1975) "Mini-Mental State". A practical method for grading the cognitive state of patients for the clinician. Journal of Psychiatric Research, 12, 189-198.

Geerlings, M. I., Jonker, C., Bouter, L. M., et al (1999) Association between memory complaints and incident Alzheimer's disease in elderly people with norma baseline cognition. American Journal of Psychiatry, I56, 53I-537.

Gurland, B. J., Fleiss, J. L., Goldberg, K., et al (1976) A semi-structured clinical interview for the assessment of diagnosis and mental state in the elderly: the Geriatric Mental State Schedule. II. A factor analysis. Psychological Medicine, 6, 45I-459.

Henderson, A. S., Korten, A. E., Jacomb, P. A., et a (1997) The course of depression in the elderly: longitudinal community-based study in Australia. Psychological Medicine, 27, I19-129.

Hooijer, C., Jonker, C., Dewey, M. E., et al (199I) A standardized interview for the elderly (GMS): reliability studies comparing the Dutch language version with the original. International Journal of Geriatric Psychiatry, 6, $7 !-79$

Jonker, C., Schmand, B., Lindeboom, J., et al (1998) Association between apolipoprotein E epsilon4 and the rate of cognitive decline in community-dwelling elderly individuals with and without dementia. Archives of Neurology, 55, 1065-1069.

Katzman, R. (1993) Education and the prevalence of dementia and Alzheimer's disease. Neurology, 43, 13-20.
Launer, L. J., Dinkgreve, M. A. H. M., Jonker, C., et al (1993) Are age and education independent correlates of the Mini-Mental State Exam performance of community-dwelling elderly? Journal of Gerontology, $\mathbf{4 8}$ 27I-277.

Meyers, B. S. \& Bruce, M. L. (1998) The depressiondementia conundrum. Integrating clinical and epidemiological perspectives. Archives of General Psychiatry, 55, 1082-1083.

Migliorelli, R., Teson, A., Sabe, L., et al (1995) Prevalence and correlates of dysthymia and major depression among patients with Alzheimer's disease. American Journal of Psychiatry, 152, 37-44.

Ott, B. R. \& Fogel, B. S. (1992) Measurement of depression in dementia: self vs clinical rating. International Journal of Geriatric Psychiatry, 7, 899-904.

Radloff, L. S. \& Teri, L. (1986) Use of the CES-D with older adults. Clinical Gerontology, 5, 119-136.

Roth, M., Huppert, F. A., Tym, E., et al (1988) CAMDEX. The Cambridge Examination for Menta Disorders of the Elderly. Cambridge: Cambridge University Press.

Stern, Y., Gurland, B., Tatemichi, T. K., et al (1994) Influence of education and occupation on the incidence of Alzheimer's disease. Journal of the American Medical Association, 27I, 1004-1010.

Alexander, G. E., Prohovnik, I., et al (1995a) Relationship between lifetime occupation and parietal flow: Implications for a reserve against Alzheimer's disease pathology. Neurology, 45, 55-60.

_ , Tang, M. X., Denaro, J., et al (1995b) Increased risk of mortality in Alzheimer's disease patients with more advanced educational and occupational attainment. Annals of Neurology, 37, 590-595.

Verhey, F. R. J., Rozendaal, N., Ponds, R.W. H. M., et al (1993) Dementia, awareness and depression. International Journal of Geriatric Psychiatry, 8, 85I-856.

Yaffe, K., Blackwell, T., Gore, R., et al (1999) Depressive symptoms and cognitive decline in nondemented elderly women. A prospective study. Archives of General Psychiatry, 56, 425-430.

Zubenko, G. S. \& Moossy, J. (1988) Major depression in primary dementia. Clinical and neuropathologic correlates. Archives of Neurology, 45, II82-1186.

Zweig, R. M., Ross, C. A., Hedreen, J. C., et al (1988) The neuropathology of aminergic nuclei in Alzheimer's disease. Annals of Neurology, 24, 233-242. 